\title{
Evaluating the dynamic impacts of urban form on transportation and environmental outcomes in US cities
}

\author{
S. B. Kashem • A. Irawan $\cdot$ B. Wilson
}

Received: 10 December 2013/Revised: 18 March 2014/ Accepted: 13 May 2014/Published online: 27 May 2014

(C) Islamic Azad University (IAU) 2014

\begin{abstract}
Previous urban sprawl studies have typically taken a cross-sectional approach without examining how sprawling urban areas are performing over time. Longitudinal studies of individual or household travel behavior and built-environment preference have made some progress in this direction, but very few studies have explored the longitudinal interaction of urban form with transportation and environmental outcomes. This study begins to fill this gap by evaluating the transportation and environmental impact dynamics of several key dimensions of urban sprawl: density, land use mix, centrality, and street connectivity. The central hypothesis is that while the built environment is durable and development patterns change slowly, the impacts of urban sprawl are dynamic rather than static and are accelerated in more sprawling cities relative to less sprawling cities. To test this hypothesis, a panel dataset of 7 years (2000-2007) was developed for 60 Metropolitan Statistical Areas of the US and a hybrid modeling framework that incorporates fixed and random effects is applied to evaluate different transportation and environmental outcomes over time. We found that the influence of urban centrality or the strength of urban subcenters on the travel pattern of commuters and transit users is dynamic. This suggests that people living in cities with stronger centers drive less and use public transportation more over time. For environmental outcomes, we found that cities with higher density have experienced a significant decrease in ambient ozone and $\mathrm{PM}_{2.5}$ concentrations after controlling city-specific variables.
\end{abstract}

S. B. Kashem $(\varangle) \cdot$ A. Irawan · B. Wilson Department of Urban and Regional Planning, University of Illinois at Urbana-Champaign, 111 Temple Buell Hall, MC-619, 611 Lorado Taft Drive, Champaign, IL, USA

e-mail: kashem1@illinois.edu
Keywords Air quality - Congestion - Sprawl - Transit . Urban form

\section{Introduction}

The relationship between urban form and transportation is one of the most extensively studied topics in the urban planning literature. However, with increased attention on sustainable development and climate change adaptation throughout the world, the links between urban form and transportation demand more scrutiny as a means of informing more effective public policy. Whether compact urban development is the most sustainable urban form remains a hotly debated topic among urban planning scholars (Neuman 2005; Echenique et al. 2012). A significant amount of research has been conducted to define and quantify urban sprawl (Wassmer 2000; Galster et al. 2001; Tsai 2005); to evaluate its impact on environment, society, transportation, economy, and energy efficiency (Stone 2008; Brueckner and Largey 2008; Carruthers and Ulfarsson 2003; Holden and Norland 2005), and to evaluate alternative policy measures for achieving sustainable urban form (Nelson and Moore 1996; Song and Knaap 2004). However, what currently draws the most attention from researchers in this arena is the connection between transportation and climate change. In the USA, transportation is responsible for about $30 \%$ of the total carbon dioxide $\left(\mathrm{CO}_{2}\right)$, which is the primary contributor to the greenhouse effect (EPA 2006). In addition to climate change, the impacts of transportation on urban air quality and pollution are also widely recognized (Frank et al. 2000, 2006; Grazi et al. 2008; Tuzkaya 2009). With rapid urbanization throughout the world, these concerns resonate in the planning processes of a growing number of cities that are 
developing strategies for sustainable urban development (Runhaar et al. 2009; Yigitcanlar and Teriman 2014). By shaping the spatial settings for human activities through tools like zoning, land use planning is considered a fundamental- and long-term approach for mitigating the environmental impact of transportation (Hong et al. 2013). Promoting high density, compact, and mixed-use urban development is widely viewed as an effective planning strategy for increasing the efficiency of public transportation, decreasing dependence on automobiles, and subsequently reducing vehicle miles traveled (VMT) and emissions. But, these propositions are also widely debated (Gordon et al. 1989; Malpezzi 1999; Neuman 2005) and the limitations of present methodological approaches are also generally accepted (Handy 2005; Brownstone 2008; Cao et al. 2009). This study contributes to these ongoing debates by leveraging innovative statistical methods to model the nonlinear impacts of sprawling development on transportation and environmental outcomes over time. A total of 60 metropolitan areas of the USA are explored in this study over a period of 7 years (2000-2007).

Most of the previous studies on urban form have taken a cross-sectional approach by evaluating alternative development patterns and their outcomes at one time period, without considering how the impacts of those development patterns change over time (e.g. Zolnik 2011; Hong et al. 2013; Bereitschaft and Debbage 2013). We explored these longitudinal impacts and considered sprawl as different patterns of density, land use mix, urban centrality, and street pattern (Ewing et al. 2002). Sprawling development is not monolithic and exhibits variation across each of these four dimensions, which suggests differential impacts on the environment and transportation (Ewing et al. 2003). We hypothesize that changes in population and transit investment mediate the impacts of sprawling development and employ an innovative statistical modeling approach to test this proposition.

Urban sprawl: definitions and quantifications

Urban sprawl is often described as low density, leapfrog development occurring at the edge of a city (Ewing 1997), but due to the complex and multifaceted nature of this phenomenon there is no universally accepted definition (Knaap et al. 2005). Despite its diverse and pliable nature, there have been numerous attempts to establish a unified definition of this elusive phenomenon. According to The Sierra Club (1999), sprawl is 'low-density development beyond the edge of service and employment, which separates where people live from where they shop, work, recreate and educate - thus requiring cars to move between zones.' Other researchers have broadened this basic definition based on the spatial separation of activities to include the spatial characteristics of land ownership or development control (e.g. Richmond 1995; Peiser 2001).

Plurality of both focus and intent when defining urban sprawl is an enduring theme in the literature (Ewing 1997; Gordon and Richardson 1997; Ewing et al. 2003). The search for a more precise definition of sprawl becomes even more difficult when differences in patterns and processes of urban growth in various countries and regions are considered. Despite these variations, there have been efforts to establish a definition that is abstract and flexible, yet useful for research and practice. Sprawl can be viewed both from aggregate and disaggregate standpoints. The former indicates attention to the overall three-dimensional structure of the urbanized area (settlement size and density) and the latter emphasizes spatial pattern within the urbanized area. To date, a significant number of studies have been conducted to identify measures and indices to quantify sprawl, but disagreement remains as to which techniques are best. The most widely used measure of urban form is density, measured by the land consumption per capita. Pioneering work by Torrens and Alberti (2000) determined the density level at which urban form can be considered sprawling, but density or settlement size can only provide an aggregate measure of urban form. In addition to density, Galster et al. (2001) suggested seven other measures including continuity, concentration, clustering, centrality, nuclearity, mixed uses, and proximity. Tsai (2005) suggests the Gini coefficient and Moran coefficient (also called Moran's I) to measure the distribution and clustering of development, respectively. Ewing et al. (2002) used 22 variables to evaluate urban sprawl across four indicators: residential density, neighborhood land use mix, strength of activity centers, and accessibility of street network. This study makes use of the sprawl measures calculated by Ewing et al. (2002) due in part to data availability constraints, but also because of the ease of interpretation and widespread implementation of this approach.

Impacts of sprawl on urban transportation

Urban sprawl can negatively impact urban transportation system in many ways. Sprawling development patternsdue to sparsely located housing, employment, and other facilities-reinforce dependence on private automobiles. However, the causal relationships between sprawling development and its transportation impacts are more complex. The relatively low cost of fuel and automobiles coupled with heavy investment in road construction make it easier to travel longer distances, which encourages sprawling development. On the other hand, as public transport cannot effectively serve low density, scattered development people have no choice but to rely on their automobiles. These issues have already been evaluated by a 
number of studies. Newman and Kenworthy (1989) published one of the most influential studies in this area by showing how automobile dependency and gasoline consumption are highly correlated with urban density. Dieleman et al. (2002) also concluded that compact urban form reduces car dependency in the context of Netherlands. In an effort to illuminate the underlying drivers of this effect, Ewing et al. (2003) showed how different urban transportation characteristics (walking, transit use, etc.) are influenced by urban sprawl, finding that higher residential density and greater centrality were associated with higher transit and walk shares of commute trips, but not with greater average commute times.

The transportation impacts of sprawl, particularly in terms of the location of employment centers and commuting times, are still a debated issue. Some researchers found that higher density employment may be associated with higher commuting times (Gordon et al. 1989; Malpezzi 1999), and low-density workplace locations are associated with lower commute times (Sultana 2000; Crane and Chatman 2003), while others found mixed results or did not find any relation to commuting at all (Gordon et al. 2004; Sarzynski et al. 2006). This 'commuting paradox' was explained by the likelihood that households and firms were rationally relocating to reduce commuting times, and that this spatial adjustment can be more easily made in dispersed metropolitan space with many alternative employment centers and residential location choices (Gordon et al. 1991; Levinson and Kumar 1994; Sultana 2000). Dubin (1991), Crane and Chatman (2004), Zhao et al. (2011) all found that the decentralization of employment to the suburbs decreased commuting times. On the other hand, Sultana and Chaney (2003) and Weber and Sultana (2007) showed that commuting times are higher in areas with low density. Overall, sprawl is argued to be associated with longer travel times because sprawl development is spread out over larger land areas and destinations are farther away than in compact development (Zolnik 2011).

Recent studies on commuting patterns have examined fast-growing areas with low-density development (sprawl) and their commuting characteristics. Weber and Sultana (2007) found that low-density and fast-growing areas are associated with longer commutes. Sarzynski et al. (2006) also found that faster-growing cities have longer commute times. Sultana and Weber (2013) studied the concept of growth wave and found that recent housing developments have longer commuting time than older part of the cities, but this commuting time will subside as these areas age. Studies have also examined the relations between population density and transit ridership; most of them confirm that areas with lower population densities have fewer journeys by public transport. Higher population density was found to have a significant positive relationship with use of public transport and significant negative relationship with automobile use (Levinson and Kumar 1997; Filion et al. 2006).

It can be seen here that the debate concerning sprawling development and its impact on transportation is far from settled. While some researchers have found a definite link between urban form and travel behavior (Ewing et al. 2003; Dieleman et al. 2002; Handy et al. 2005; Bhat and Guo 2007), there are others who did not find any significant relationship (Crane and Crepeau 1998; Eid et al. 2008). However, the familiar adage 'correlation is not causality' applies here and while most of the studies to date have focused on correlation, causality is yet to be established. This article evaluates the dynamics of impacts created by urban form and in so doing, clarifies the causal relationships between sprawl and its transportation and environmental outcomes.

\section{Environmental impacts of sprawl}

Studies of urban form and the environment have well documented the mechanisms by which urban form and land use change might influence air quality, air pollutant emissions, and the release of $\mathrm{CO}_{2}$ (Lariviere and Lafrance 1999; Borrego et al. 2006; Stone 2008; Marshall 2008; Liao et al. 2013). A limited number of studies have empirically evaluated the direct associations between urban form and the emission or concentration of air pollution (Stone 2008; Schweitzer and Zhou 2010; Bechle et al. 2011; Clark et al. 2011). Although it is generally assumed that the relationship between land use and vehicle travel holds implications for tailpipe emissions and air quality, only a handful of studies has sought to statistically link urban form to vehicle emissions directly (Stone 2008). Frank et al. (2000) found statistically significant relationships between household density, employment density, street connectivity, and tailpipe emissions. A recent study concluded that metropolitan areas exhibiting higher levels of urban sprawl, generally exhibited higher concentrations and emissions of air pollution and $\mathrm{CO}_{2}$ when controlling for population, land area, and climate (Bereitschaft and Debbage 2013).

Urban form can also affect air quality by influencing local meteorology, including the urban heat island (UHI) effect, and the energy efficiency of buildings (Weng 2003; Ewing and Rong 2008). Urban spatial structure can influence ozone formation through two distinct mechanismsthe quantity of precursor emissions from vehicle travel and the meteorological effects of urban heat island formation (Stone 2008). Ewing et al. (2003) and Stone (2008) observed that the large US cities with higher levels of urban sprawl (i.e., lower densities, less street connectivity, less mixed land use), experienced significantly higher $\mathrm{O}_{3}$ precursor emissions, higher $\mathrm{O}_{3}$ concentrations, and significantly more $\mathrm{O}_{3}$ exceedances. 
But studies at smaller scales sometimes yield mixed results. Schweitzer and Zhou (2010) took a finer scale approach and found that neighborhoods in less sprawling US metropolitan areas, generally exhibited lower concentrations of $\mathrm{O}_{3}$, but higher $\mathrm{O}_{3}$ and $\mathrm{PM}_{2.5}$ exposures due to a greater concentration of people living in areas with higher air pollutant concentrations. Through an analysis of 111 U.S. Census defined urban areas, Clark et al. (2011) found that those with more centralized populations were associated with lower population-weighted $\mathrm{PM}_{2.5}$ and $\mathrm{O}_{3}$ concentrations, whereas those with higher population densities were associated with significantly higher populationweighted $\mathrm{PM}_{2.5}$ concentrations. So, in the case of environmental outcomes also we see conflicting results on the impacts of urban sprawl. Further, most of the relevant studies have evaluated these impacts using a cross-sectional approach, without considering how urban form influences air quality over time.

Gaps in existing urban form studies

The previous two sections summarized existing studies of the impacts of urban form on the environment and transportation and highlighted key points of debate as well as important inconsistencies. By applying a cross-sectional design, most of the existing studies offer a snap shot of travel behavior and environmental outcomes in different places at one point in time and while these studies reveal the correlation between urban form and its impacts, they do not prove causality (Handy 2005). In the case of sprawl and transportation, researchers have argued about the possibility of a 'selfselection' bias which is particularly ignored in a cross-sectional framework (Brownstone and Golob 2009; Hong et al. 2013). The idea is that individuals who would prefer to walk or take transit than drive choose to live in more compact neighborhoods that are conducive to walking and taking transit (Handy 2005). In this case, urban form does not influence their transportation pattern, rather their desire to live in certain lifestyle (i.e. drive less, walk more, or vice versa) may have influenced the observed transportation outcomes.

A few studies have attempted to address the self-selection issue. Handy and Clifton (2001) found that residents with a higher frequency of walking to the store (compared to other neighborhoods) did in fact choose their neighborhood because they like to walk to the store. On the other hand, the travel impacts of neighborhood characteristics are found to be significant in many studies even after controlling for the influence of residential self-selection (Cao et al. 2009; Hong et al. 2013). After reviewing possible methodologies that can be adopted to relieve the selfselection impact, Mokhtarian and Cao (2008) developed six categories: direct questioning, statistical control, instrumental variable models, sample selection models, other joint models (joint discrete choice models and structural equations models), and longitudinal designs. A more realistic approach is to employ a longitudinal research design, following the same households or individuals over time (Hong et al. 2013). This would allow the dynamic processes to be explored by tracking individuals, households, and businesses over time. However, this approach is infeasible in most cases because few metropolitan organizations (MPOs) maintain panel data on household location and travel.

Excluding individual or neighborhood level analysis, the literature still lacks studies with an adequate focus on the longitudinal interaction patterns between urban form and its impacts on transportation and the environment. Sarzynski et al. (2006) significantly advanced cross-sectional research on commuting by using more elaborate urban form variables (sprawl indices) and addressing potential endogeneity and time-lag effects between urban structure and congestion. However, this study also did not take a fully longitudinal approach that would have revealed how different urban form patterns have performed over time. In response to this gap, this article adopts an explicitly longitudinal approach and explores the dynamic impacts of urban form on transportation and environment in US cities. Although we are also not controlling the issue of residential self-selection (partly due to data unavailability, and considering multi-city focus of this study), we believe that our methodological approach is a valuable contribution to present debates on sprawl impacts.

\section{Materials and methods}

The primary data sources used in this study are sprawl measures for major metropolitan areas of the USA calculated by Ewing et al. (2002) and the Texas Transportation Institute's (TTI) 2012 Annual Urban Mobility Report, which provides transportation data for major metropolitan areas for the period 1982-2011. Control variables are based on data collected from other sources and described below.

\section{Urban sprawl measures}

Ewing et al. (2002) were the first to develop a multidimensional metric of the sprawl phenomenon, using 22 variables that represent different aspects of development patterns. Using principal components analysis, they grouped these variables into four factors ${ }^{1}$ or dimension of sprawl:

- Residential density (density factor)

\footnotetext{
${ }^{1}$ Ewing et al. (2002) also calculated an overall sprawl score combining the four measures of sprawl, but this composite index is not used in this study.
} 


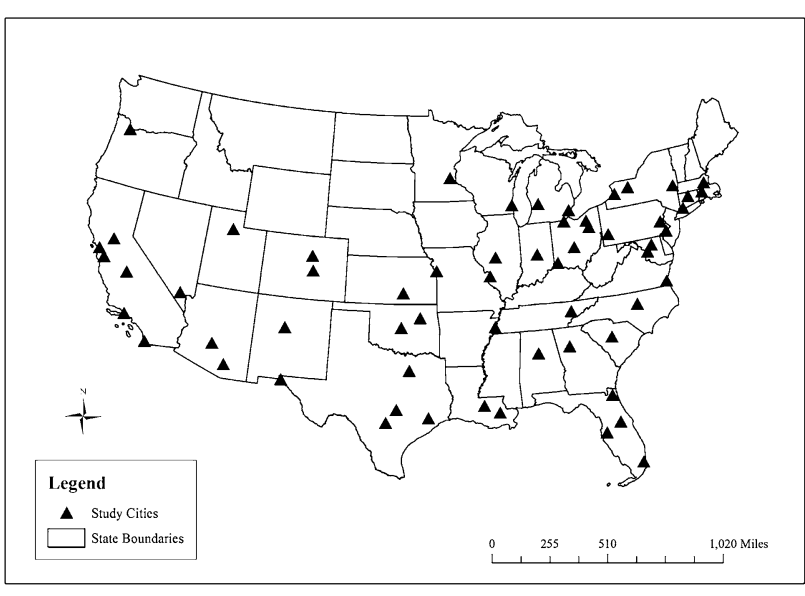

Fig. 1 Study cities in the USA

- Neighborhood mix of homes, jobs, and services (mix factor)

- Strength of activity centers and downtowns (centers factor)

- Accessibility of the street network (street factor)

The 83 Metropolitan Statistical Areas (MSAs) included in their analysis captured nearly half of the US population and the Ewing et al. (2002) database remains one of the most comprehensive assessments of metropolitan development patterns available to date. We used these sprawl measures, but only 60 MSAs were selected for analysis due to data availability constraints and a concern about outlier effects from some of the larger MSAs (Fig. 1). For the sake of comparability, Ewing et al. (2002) standardized the four sprawl factors so that the average of each factor is represented by a score of 100 , so metro areas with scores above 100 are more compact than metro areas with scores below 100. Ewing et al. calculated these four sprawl measures for the year 2000, and in this study, we assumed that urban sprawl pattern would not change significantly within the study time period (2000-2007). Changes in land use or urban form usually affect transportation outcomes more slowly than shifts in demographic characteristics or preferences (Sarzynski et al. 2006). Because causality requires temporal precedence, it is more appropriate to consider urban form as measured at a base time period rather than at the current period to statistically control the effect of urban form. These considerations, coupled with the fact that annual versions of the multidimensional sprawl index are not available, were the basis for our decision to hold urban form constant over the 7 year study period. The built environment is durable, and past development decisions are not easily undone, particularly in the short term. Also, the onset of the foreclosure crisis and economic recession in 2008 and its implications for suburban neighborhoods in particular (Niedt and Martin 2013) may have biased our results, and so the study period was restricted to the years 2000-2007.

Transport and environmental outcomes

Transport outcome variables considered in this study are taken from the 2012 Annual Urban Mobility Report prepared by the Texas Transportation Institute (TTI). This report compiled and calculated data from different sources and provided a comprehensive database of different transportation parameters for large metropolitan areas of the USA over the period of 1982-2011. All of the transportation measures considered in this report for each year and every city are compiled in a spreadsheet that can be downloaded from the TTI website. ${ }^{2}$ A total of three transportation measures are considered in this study and two of these focus on overall travel patterns by automobiles and transit—daily vehicle miles traveled (DVMT) per capita and annual unlinked passenger trips per capita in public transportation. The third transportation outcome variable is related to congestion-percent of congested travel (as percentage of peak VMT).

Two environmental outcome variables are considered and both are concerned with air quality-ambient concentration of $\mathrm{O}_{3}$ (highest fourth daily maximum 8-h concentration in $\mathrm{ppm}$ ) and highest weighted annual mean concentration of $\mathrm{PM}_{2.5}(\mu \mathrm{g} / \mathrm{m} 3)$. Tropospheric ozone $\left(\mathrm{O}_{3}\right)$ and fine particulate matter $\left(\mathrm{PM}_{2.5}\right)$ are known contributors to life-threatening cardiovascular and pulmonary illnesses (Laden et al. 2006; Jacobson 2008; Jerrett et al. 2009) and although ozone is not strictly related to transportation, the maximum ozone level in the metropolitan area is closely linked to motor vehicle use (Ewing et al. 2003). These data were collected from the U.S. Environment Protection Agency's (US EPA) air trend database, ${ }^{3}$ which contains data from 1990 to 2012. Because this study focuses on the 2000-2007 period, not all of the available information was used. We also chose to use nonpoint source emissions in the analysis and to exclude emissions by large point-source industrial facilities, which are not expected to be affected significantly by urban form.

\section{Control variables}

Control variables used in this study include estimated population (2000-2007), average state fuel cost (\$/gallon), percentage of workers 16 years and over who did not work at home, per capita personal income, average temperature

\footnotetext{
2 These data can be accessed at http://tti.tamu.edu/documents/ums/ congestion-data/complete-data.xls.

3 These data can be accessed at http://www.epa.gov/airtrends/pdfs/ AirQualityTrendsbyCity2000-2012.xlsx.
} 
of metropolitan areas, total fund for transit (operating and capital), and directional route miles (fixed-guideway and mixed-traffic when applicable) for transit. Data on the first two control variables were collected from the Urban Mobility Report of TTI, while data on working commuters come from American Community Survey (2005-2009) and data on per capita personal income come from the Survey of Current Business compiled by the U.S. Bureau of Economic Analysis. ${ }^{4}$ Data on public transit funding and infrastructure are collected from National Transit Database (NTD) managed by the Federal Transit Administration. The historic data files of NTD include some key data elements on the transit system in different US cities reported to the National Transit Database Annual Module from 1991 to 2011. Total funds for transit include all funds from federal, state, local, and other sources, which are applied to transit (operating and capital). The directional route miles (DRM) includes the mileage in each direction over which public transportation vehicles travel while in revenue service. These measures are included considering the fact that investments and the availability of public transit should influence the transportation outcomes of different cities. Table 1 shows descriptive statistics of the variables used in this study.

Table 2 presents the correlation coefficients for each of the dependent variables with the four urban sprawl measures. A significant negative coefficient for daily VMT per capita (DVMTperCapita) across all four measures of sprawl indicates that with decreasing levels of sprawl, people are driving shorter distances. Similarly, correlations of annual passenger trips per capita in public transport (AnnualtripperCapita) across different measures of urban sprawl indicate a significant influence of the density factor and street factor. The correlation coefficient of the mix factor and centers factor indicate no significant influence of mixed use and very small negative influence of urban centrality. The result of the centers factor is counterintuitive, because we usually believe that cities with stronger sub-centers should facilitate transit usage (or vice versa, transit developments promote stronger sub-centers). The problem here is that these correlations are measured for all cities irrespective of their level of transit development. As we will see later through the regression analysis, after controlling transit availability, population, and other factors, the centers factor becomes a significant predictor of transit usage.

For congested travel (as a percentage of peak VMT), each of the sprawl factors was found to have a significant effect, with the exception of the mix factor. In this case, different sprawl measures are indicating different trends.

\footnotetext{
${ }^{4}$ Accessed at http://www.census.gov/compendia/statab/2012/tables/ 12s0683.xls.
}

The significant positive correlation coefficient for the density factor (0.527) indicates that higher density increases congestion during peak period travel. But on the other hand, a significant negative coefficient of the centers factor $(-0.480)$ indicates that cities with stronger sub-centers (i.e. higher value of centers factor) experience less congestion during peak travel periods. For the level of ozone concentration $\left(\mathrm{O}_{3} \mathrm{ppm}\right)$ across different measures of urban sprawl, negative coefficients of density and street factor indicate that lesser level of ozone concentration is correlated with lesser level of sprawl. Correlations for annual mean concentrations of $\mathrm{PM}_{2.5}$ across the different sprawl measures shows trends similar to ozone concentration.

\section{Regression modeling framework}

In order to estimate the dynamic impacts of urban form on transportation and environmental outcomes, we applied a hybrid modeling framework (Allison 2009) that combines both fixed effects and random effects for panel data analysis. Fixed effects models can evaluate the effects of timevarying factors on certain time-varying outcomes, controlling for unmeasured year-specific and case-specific effects (England et al. 1988). One important assumption of fixed effects models is that the time-invariant characteristics of the individual cases are unique to those cases and they are allowed to be correlated with other time-varying individual characteristics. However, fixed effects models cannot evaluate the influence of time-invariant characteristics on the time-variant outcomes. On the other hand, random effects models can accommodate time-invariant predictors and be used to analyze their influence on the outcomes. The estimates of random effects models are more efficient, but those estimates can be biased if the restrictions of the model are not met (Allison 2009). In this case, the unobserved variables are assumed to be uncorrelated with all observed variables. The hybrid regression approach adopted here combines the virtues of the fixed effects model and the random effects model in that it can estimate the effects of the time-invariant variables, but is less prone to bias due to other unmeasured variables. This study hypothesizes that the impacts of urban sprawl are dynamic rather than static and increase in a nonlinear way depending on the characteristics of each metropolitan area; therefore, the estimation also needs to control for other relevant variables. In order to test this hypothesis, it is necessary to consider the influence of time-invariant factors (urban sprawl) on time-varying responses (i.e., transportation and environmental outcomes) controlling for different other time-varying and time-invariant characteristics (e.g., population, fuel cost, per capita income, average temperature, transit availability, etc.). With this aim in mind, we applied a hybrid regression approach which can 
Table 1 Descriptive statistics (60 MSAs, 480 observations)

\begin{tabular}{|c|c|c|c|}
\hline Description & Variable name & Mean & SD \\
\hline \multicolumn{4}{|l|}{ Dependent variables } \\
\hline Daily vehicle miles of travel (VMT) per capita (2000-2007) & DVMTperCapita & 19.26 & 2.83 \\
\hline Annual unlinked passenger trips per capita in public transportation (2000-2007) & PassTripperCapita & 25.97 & 22.98 \\
\hline Congested travel (\% of peak VMT) (2000-2007) & CongstTravel & 48.87 & 18.95 \\
\hline Highest fourth daily maximum 8-hour concentration (ppm) (2000-2007) & $\mathrm{O} 3 \mathrm{ppm}$ & 0.08 & 0.01 \\
\hline Highest weighted annual mean concentration of $\mathrm{PM}_{2.5}(\mu \mathrm{g} / \mathrm{m} 3)(2000-2007)$ & PM25 W & 12.34 & 2.92 \\
\hline \multicolumn{4}{|l|}{ Independent variables } \\
\hline Density factor for 2000 & den_f & 95.28 & 12.41 \\
\hline Mix factor for 2000 & mix_f & 101.99 & 20.35 \\
\hline Centers factor for 2000 & cent_f & 103.5 & 20.24 \\
\hline Street factor for 2000 & str_f & 96.86 & 22.28 \\
\hline \multicolumn{4}{|l|}{ Control variables } \\
\hline Total funding for transit (operating and capital) per capita (\$) (2000-2007) & $\begin{array}{l}\text { Fundshr } \\
\text { (Mfundshr, Dfundshr) }^{\mathrm{a}}\end{array}$ & 119.6 & 109.04 \\
\hline Directional route miles for transit per capita (miles) (2000-2007) & $\begin{array}{l}\text { DRMshr } \\
(M d r m s h r, D d r m s h r)^{\mathrm{a}}\end{array}$ & 0.001 & 0.0005 \\
\hline Estimated population (thousands) (2000-2007) & $\begin{array}{l}\text { Pop } \\
(\text { Mlnpop, Dmlnpop })^{\mathrm{a}}\end{array}$ & 1642 & 1287 \\
\hline Average state fuel cost (\$/gallon) (2000-2007) & $\begin{array}{l}\text { fuel_cost } \\
(\text { Mgas, Dgas })^{\mathrm{a}}\end{array}$ & 2.003 & 0.579 \\
\hline Percentage of workers 16 years and over who did not work at home (thousands) & wrk_16 & 62.29 & 0.09 \\
\hline Per capita personal income $(\$)(2000-2007)$ & pcinc & 35358.52 & 7506.68 \\
\hline Average temperature (1971-2001) & avg_temp & 57.19 & 7.79 \\
\hline
\end{tabular}

a These variables are taken as both MSA-specific mean over study years (2000-2007) and deviation from their respective means

Table 2 Correlation matrix for sprawl factors and transportation and environment outcomes

\begin{tabular}{|c|c|c|c|c|c|}
\hline Sprawl factors & DVMTperCapita & PassTripperCapita & CongstTravel & $\mathrm{O} 3 \mathrm{ppm}$ & PM2.5 W \\
\hline Mix factor & $\begin{array}{l}-0.355^{* * *} \\
(0.000)\end{array}$ & $\begin{array}{l}0.024 \\
(0.607)\end{array}$ & $\begin{array}{l}-0.023 \\
(0.622)\end{array}$ & $\begin{array}{l}0.086 \\
(0.065)\end{array}$ & $\begin{array}{l}-0.127 * * \\
(0.008)\end{array}$ \\
\hline Density factor & $\begin{array}{l}-0.407 * * * \\
(0.000)\end{array}$ & $\begin{array}{l}0.644 * * * \\
(0.000)\end{array}$ & $\begin{array}{l}0.598 * * * \\
(0.000)\end{array}$ & $\begin{array}{l}-0.290 * * * \\
(0.000)\end{array}$ & $\begin{array}{l}-0.316^{* * *} \\
(0.000)\end{array}$ \\
\hline Centers factor & $\begin{array}{l}-0.226^{* * *} \\
(0.000)\end{array}$ & $\begin{array}{l}-0.009 \\
(0.840)\end{array}$ & $\begin{array}{l}-0.472 * * * \\
(0.000)\end{array}$ & $\begin{array}{l}-0.030 \\
(0.528)\end{array}$ & $\begin{array}{l}-0.064 \\
(0.179)\end{array}$ \\
\hline Street factor & $\begin{array}{l}-0.250^{* * *} \\
(0.000)\end{array}$ & $\begin{array}{l}0.369 * * * \\
(0.000)\end{array}$ & $\begin{array}{l}0.463 * * * \\
(0.000)\end{array}$ & $\begin{array}{l}-0.291 * * * \\
(0.000)\end{array}$ & $\begin{array}{l}-0.342^{* * *} \\
(0.000)\end{array}$ \\
\hline
\end{tabular}

Numbers in parentheses below coefficients are $\mathrm{p}$ values

* 0.05 probability level, $* * 0.01$ probability level, *** 0.001 probability level

estimate both the time-variant and time-invariant explanatory variables.

In its most general specification, the dependent variable is measured on an interval scale and is assumed to be linearly dependent on a set of predictors. In the present case, we have a set of metropolitan areas $(i=1, \ldots \ldots, 60)$, each of which is measured at different time periods $(t=2000, \ldots \ldots, 2007)$. Let $y_{i t}$ be the dependent variable, $x_{i t}$ be a set of predictor variables that vary over time and $z_{i}$ be another set of predictors that do not vary over time. Therefore, the basic model for $y$ is given in (1).

$y_{i t}=\mu_{t}+\beta x_{i t}+\gamma z_{i}+\alpha_{i}+\varepsilon_{i t}$

Here, $\mu_{t}$ is an intercept for each period, and $\beta$ and $\gamma$ are vectors of coefficients. The two error terms, $\alpha_{i}$ and $\varepsilon_{i t}$, behave somewhat differently from each other. There is a different $\varepsilon_{i t}$ for each metropolitan area at each point in time, but $\alpha_{i}$ only varies across metropolitan areas, not over 
time. Here, $\alpha_{i}$ is regarded as representing the combined effect on $y$ of all unobserved variables that are constant over time. On the other hand, $\varepsilon_{i t}$ represents purely random variation at each point in time which is assumed to be with mean zero and with constant variance (for all $i$ and $t$ ). It is considered here that $\varepsilon_{i t}$ at any one period is independent of $x_{i t}$ at any other period, which means that $x_{i t}$ is strictly exogenous. Fixed effects analysis allows for any correlation between $\alpha_{i}$ and $x_{i t}$, but random effects analysis considers that they are uncorrelated. In fixed effects model, the coefficients and errors of time-invariant variables $\left(\gamma\right.$ and $\left.\alpha_{i}\right)$ are eliminated and so, we cannot estimate the influence of those time-invariant factors.

Under the hybrid regression framework, time-varying regressors are transformed into deviations from their MSAspecific means, but the dependent variable remains untransformed. Then, a random effects model is estimated to ensure that the standard errors reflect the dependence among the multiple observations for each MSA. According to Allison (2009), inclusion of means for time-varying variables in addition to the mean deviations of those variables is based on two rationales. Firstly, it produces better estimates of the effects of other time-invariant variables. Secondly, by comparing their coefficients with those of the mean-deviation variables, it helps to test the assumption of the random effects model (i.e., whether $\alpha_{i}$ term is uncorrelated with other observed variables). If the assumptions of random effects model are correct, then the mean-deviation coefficient should be the same as the mean coefficient for each variable (apart from sampling variability). This test was conducted in Stata (using a Wald test) after applying the random effects model.

\section{Results and discussion}

As discussed in the previous section, the means and mean deviations of the time-varying variables were calculated for each of the MSAs when estimating a model using the hybrid regression approach. So, instead of the actual timevarying variables (as shown in Table 1), the model now contains their means and mean deviations (e.g., fuel cost becomes $M f u e l$ and $D f u e l$, etc.). Also, some of the variables were transformed to improve the normality of their

Table 3 Estimation results of the hybrid regression model for travel pattern outcomes

\begin{tabular}{|c|c|c|c|}
\hline & \multicolumn{3}{|l|}{ Dependent variables } \\
\hline & lnDVMTperCapita & lnPassTripperCapita & lnCongstTravel \\
\hline \multicolumn{4}{|c|}{ Independent variables (sprawl measures) } \\
\hline Mix factor $\left(m i x \_f\right)$ & $0(0.001)$ & $-0.001(0.003)$ & $0(0.002)$ \\
\hline Density factor $\left(\operatorname{den}_{-} f\right)$ & $-0.002(0.003)$ & $0.001(0.01)$ & $0.001(0.007)$ \\
\hline Centers factor $\left(\right.$ cent $\_$) & $-0.002(0.001)^{*}$ & $0.009(0.003)^{* *}$ & $-0.003(0.003)$ \\
\hline Street factor $\left(s t r \_f\right)$ & $0(0.001)$ & $-0.004(0.003)$ & $0.005(0.002)^{*}$ \\
\hline \multicolumn{4}{|l|}{ Control variables } \\
\hline$w k 16 r t$ & $0.663(0.219)^{* *}$ & $-0.679(0.68)$ & $0.993(0.553)$ \\
\hline Pcinc & $0(0)$ & $0(0)$ & $0.00001(0)^{* * *}$ \\
\hline avg_temp & $0.001(0.002)$ & $0.009(0.008)$ & $0.009(0.006)$ \\
\hline Mlnpop & $0.021(0.037)$ & $0.42(0.152)^{* *}$ & $0.332(0.088)^{* * *}$ \\
\hline Dmlnpop & $-0.443(0.048) * * *$ & $-0.455(0.255)$ & $0.648(0.105)^{* * *}$ \\
\hline Mgas & $-0.18(0.184)$ & $0.773(0.712)$ & $0.701(0.496)$ \\
\hline Dgas & $-0.007(0.025)$ & $0.002(0.091)$ & $-0.016(0.056)$ \\
\hline Mfundshr & $0.0001(0.0003)$ & $0.004(0.001)^{* * *}$ & $-0.0004(0.0006)$ \\
\hline Dfundshr & $0.0002(0.0001)^{* *}$ & $0.001(0.0002)^{* * *}$ & $-0.0002(0.0001)$ \\
\hline Mdrmshr & $-70.877(40.686)$ & $184.016(139.475)$ & $-38.143(115.052)$ \\
\hline Ddrmshr & $11.348(7.348)$ & $13.162(36.035)$ & $2.305(18.247)$ \\
\hline _cons & $3.159(0.553) * * *$ & $-2.811(2.162)$ & $-1.732(1.401)$ \\
\hline \multicolumn{4}{|l|}{$R-s q:$} \\
\hline Within & 0.5082 & 0.1208 & 0.2272 \\
\hline Between & 0.4659 & 0.7624 & 0.6466 \\
\hline Overall & 0.4684 & 0.7504 & 0.6384 \\
\hline
\end{tabular}

Estimation based on hybrid models (robust standard error in parenthesis)

$* 0.05$ probability level, $* * 0.01$ probability level, $* * * 0.001$ probability level 
distribution. The results of the regression analyses discussed here under the broad categories of the dependent variables: (1) travel pattern and congestion and (2) environmental outcomes.

\section{Travel patterns and congestion}

Table 3 presents the estimation results from the hybrid regression model applied to three of the variables related to travel pattern and congestion.

The natural log of daily vehicle miles traveled (DVMT)

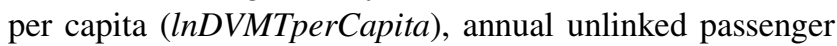
trips per capita in public transportation (InPassTripperCapita), and percent of congested travel (InCongstTravel) are the dependent variables for these three models. In both DVMT and transit usage, the center factor was found to be significantly influencing the travel patterns, but other sprawl measures did not indicate any statistically significant influence. This suggests that people living in cities with stronger centers drive less and use public transportation more over time. Beside the centrality measure, increase of population (Dmlnpop), percentage of 16 years and above age working population (wkl6rt), and per capita share of transit mile (Ddrmshr) were found to be significantly influencing the driving trends in different cities. It can be generally expected that increase of population will increase population density and thereby reduce per capita driving of a city, although it depends on availability of other transport modes (i.e. walking, transit etc.). More working population can also be expected to increase driving, but it is not clear why an increase of transit miles would increase VMT per capita (although the influence is too small). It can potentially be due to investments which are yet to come into operation. For transit ridership, population (Mlnpop) and investment for public transit were found to be significant predictors, in addition to the centers factor of a city. It follows general expectation that larger population will increase number of transit riders and increased investments for transits will attract more people to use transit service instead of driving. In the case of congestion, only the street factor was found to be significantly influencing peak travel congestion (InCongstTravel), which suggests that cities with higher street connectivity have experienced higher congestion during peak period travel over time. The control variables provide further useful insight into which factors are significantly affecting congestion in the cities. In this case, base population (Mlnpop) and increase of population (Dmlnpop) were two of the significant predictors associated with increasing congestion over time.

\section{Environmental outcomes}

For environmental outcomes, the level of land use mixing (mix factor) and density (density factor) were found to
Table 4 Estimation results of the hybrid regression model for environmental outcomes

\begin{tabular}{lll}
\hline & \multicolumn{2}{l}{ Dependent variables } \\
\cline { 2 - 3 } & O3 ppm & PM25 W \\
\hline Independent variables & (sprawl measures) & \\
Mix factor (mix_f) & $0.0001(0.0001)^{*}$ & $-0.007(0.021)$ \\
Density factor (den_f) & $-0.0006(0.0002)^{* *}$ & $-0.141(0.068)^{*}$ \\
Centers factor (cent_f) & $0(0.0001)$ & $-0.013(0.022)$ \\
Street factor (str_f) & $-0.0001(0.0001)$ & $-0.021(0.018)$ \\
Control variables & & \\
wkl6rt & $-0.0163(0.012)$ & $-7.654(4.788)$ \\
Pcinc & $0(0)$ & $0(0)$ \\
avg_temp & $0.0001(0.0001)$ & $-0.106(0.059)$ \\
Mlnpop & $0.006(0.0023)^{* *}$ & $1.102(1.007)$ \\
Dimlnpop & $0.0029(0.0089)$ & $-0.522(1.835)$ \\
Mgas & $0.008(0.0107)$ & $-0.127(4.606)$ \\
Dgas & $0.0062(0.0052)$ & $0.478(0.624)$ \\
Mfundshr & $0(0)$ & $0.006(0.007)$ \\
Dfundshr & $0(0)$ & $0.001(0.002)$ \\
Mdrmshr & $-2.2055(2.5449)$ & $-969.013(914.026)$ \\
Ddrmshr & $0.3743(1.4109)$ & $-41.373(226.886)$ \\
_cons & $0.0706(0.0294)^{*}$ & $34.81(12.983)^{* *}$ \\
R-sq: & & \\
Within & 0.338 & 0.448 \\
Between & 0.398 & 0.355 \\
Overall & 0.374 & 0.365 \\
\hline & & \\
\hline
\end{tabular}

Estimation based on hybrid models (robust standard error in parenthesis)

* 0.05 probability level, ** 0.01 probability level, *** 0.001 probability level

have a significant influence (Table 4) on air quality. This result suggests that cities with higher density have experienced lower concentrations of ozone and $\mathrm{PM}_{2.5}$ over time. On the other hand, cities with higher land use mix (mix $\_$) were found to be experiencing higher ozone concentrations, although the influence is much smaller than that of the density factor. While prior cross-sectional studies give mixed results on environmental impacts of different sprawl measures (Stone 2008; Clark et al. 2011; Bereitschaft and Debbage 2013), our longitudinal analysis shows another dimension of this pattern and suggests that cities with higher density are having better air quality over time.

Although our finding supports the arguments in favor of policy measures to encourage more compact development as a means of improving urban air quality, we also have to be careful about other implications of dense developments. Schweitzer and Zhou (2010) and Clark et al. (2011) suggest that increasing density may raise the air pollutant exposure to some urban residents. While increased population density can reduce automobile dependency, it can also concentrate people in urban neighborhoods with poor air 
quality (Schweitzer and Zhou 2010). So, we should look for innovative policy measures that will be sensitive to the concerns of social vulnerability and environmental justice, but will also ensure sustainable urban development.

\section{Conclusion}

Considerable efforts have been devoted to defining and quantifying urban sprawl so that this pattern of urban development and its associated negative consequences can be better understood (Song and Knaap 2004; Weber and Sultana 2007). However, there has been little consistency as to exactly what this phenomenon is and how it can be defined. Also, urban form studies at the city or metropolitan area scale continue to ignore or inadequately address the temporal aspects of sprawl and its many impacts. Many of the currently available analyses are based on crosssectional data, allowing a view of one 'snapshot' in time. This study begins to fill this gap by evaluating the dynamics of impacts created by urban form on the environment and transportation over time using a hybrid regression modeling framework. Our findings suggest that most of the sprawl measures considered-density, land use mixing, and street connectivity-are not exerting a significant longitudinal influence on daily vehicular travel or transit ridership. However, there is clear evidence that the sprawl measure capturing urban centrality and the strength of sub-centers is significant in understanding these relationships. Specifically, metropolitan areas with stronger sub-centers experienced a lower increase in daily driving mileage by commuters, relative to metropolitan areas that were more dispersed. At the same time, those metropolitan areas are also seeing transit ridership increase over time, even after controlling for population growth. Although our results did not indicate a significant role for density, land use mixing, or street connectivity this does not mean that these factors have no effect on transportation. Rather their impacts may have been offset by other time-varying factors (e.g., increase of population, per capita income, or fuel prices) and future research should investigate these relationships. The consistently significant influence of the centers factor is consistent with prior studies and suggests an important causal relationship between urban centrality and transportation outcomes at the metropolitan level. Our study also shows the efficacy of compact development for improving air quality of cities over time.

This study identified several key dynamics of urban sprawl impacts which were not evaluated by previous studies. One of the implications of these findings is that in order to reduce the negative impacts of sprawl on urban transportation we should focus more on the strengthening sub-centers within metropolitan areas. While the potential benefits of polycentric urban form are not a new idea, our findings offer more specific insight into how land use planning might facilitate intra-regional development patterns that are more compatible with transportation efficiency and environmental quality. While the longitudinal approach and hybrid regression framework adopted here are novel, this foundation can be enhanced by increasing the number of metropolitan areas included in the analysis and by incorporating more control variables. Future studies can contribute to ongoing debates on the impacts of urban sprawl and provide more specific direction for policy responses by further examining its temporal aspects and the methods applied in this article offer a way forward.

Acknowledgments We would like to acknowledge and cordially thank the anonymous reviewers for their constructive comments and suggestions, which helped us to significantly improve the manuscript.

\section{References}

Allison PD (2009) Fixed effects regression models. Sage Publications, Los Angeles

Bechle MJ, Millet DB, Marshall JD (2011) Effects of income and urban form on urban $\mathrm{NO}_{2}$ : global evidence from satellites. Environ Sci Technol 45:4914-4919

Bereitschaft B, Debbage K (2013) Urban form, air pollution, and CO2 emissions in large U.S. metropolitan areas. Prof Geogr 65(4):612-635. doi:10.1080/00330124.2013.799991

Bhat CR, Guo JY (2007) A comprehensive analysis of built environment characteristics on household residential choice and auto ownership levels. Transp Res Part B Methodol 41(5):506-526

Borrego C, Martins H, Tchepel O, Salmim L, Monteiro A, Miranda AI (2006) How urban structure can affect city sustainability from an air quality perspective. Environ Model Softw 21:461-467

Brownstone D (2008) Key relationships between the built environment and VMT. University of California, Irvine

Brownstone D, Golob TF (2009) The impact of residential density on vehicle usage and energy consumption. J Urban Econ 65:91-98

Brueckner JK, Largey AG (2008) Social interaction and urban sprawl. J Urban Econ 64(1):18-34

Cao XY, Mokhtarian PL, Handy SL (2009) Examining the impacts of residential self-selection on travel behaviour: a focus on empirical findings. Transp Rev 29(3):359-395. doi:10.1080/ 01441640802539195

Carruthers JI, Ulfarsson GF (2003) Urban sprawl and the cost of public services. Environ Plan B Plan Des 30(4):503-522

Clark LP, Millet DB, Marshall JD (2011) Air quality and urban form in U.S. urban areas: evidence from regulatory monitors. Environ Sci Technol 45:7028-7035

Crane R, Chatman D (2003) Traffic and sprawl: evidence from U.S. commuting, 1985 to 1997. Plan Mark 6(1):14-22

Crane R, Chatman D (2004) Traffic and sprawl: evidence from U.S. commuting 1985-1997. In: Richardson H, Bae C (eds) Urban sprawl in Western Europe and the United States. Ashgate, London

Crane R, Crepeau R (1998) Does neighborhood design influence travel?: a behavioral analysis of travel diary and GIS data. Transp Res Part D Transp Environ 3(4):225-238

Dieleman FM, Dijst M, Burghouwt G (2002) Urban form and travel behaviour: micro-level household attributes and residential context. Urban Stud 39(3):507-527 
Dubin R (1991) Commuting patterns and firm decentralization. Land Econ 67:121-129

Echenique MH, Hargreaves AJ, Mitchell G, Namdeo A (2012) Growing cities sustainably: does urban form really matter? J Am Plan Assoc 78(2):121-137

Eid J, Overman HG, Puga D, Turner MA (2008) Fat city: questioning the relationship between urban sprawl and obesity. J Urban Econ 63(2):385-404

England P, Farkas G, Kilbourne BS, Dou T (1988) Explaining occupational sex segregation and wages: findings from a model with fixed effects. Am Sociol Rev 53:544-558

EPA (2006) Greenhouse gas emissions from the U.S. transportation sector, 1990-2003. Environmental Protection Agency, Washington, DC

Ewing R (1997) Is Los Angeles-style sprawl desirable? J Am Plan Assoc 63(1):107-126

Ewing R, Rong F (2008) The impact of urban form on U.S. residential energy use. Hous Policy Debate 19(1):1-30

Ewing R, Pendall R, Chen D (2002) Measuring sprawl and its impact. Smart Growth America, Washington, DC

Ewing R, Pendall R, Chen D (2003) Measuring sprawl and its transportation impacts. Transp Res Rec 1831:175-183

Filion P, McSpurren K, Appleby B (2006) Wasted density? The impact of Toronto's residential-density distribution policies on public-transit use and walking. Environ Plan A 38:1367-1392

Frank LD, Stone B, Bachman W (2000) Linking land use with household vehicle emissions in the central Puget Sound: methodological framework and findings. Transp Res Part D 5(3):173-196

Frank LD, Sallis JF, Conway TL, Chapman JE, Saelens BE, Bachman W (2006) Many pathways from land use to health: associations between neighborhood walk ability and active transportation, body mass index, and air quality. J Am Plan Assoc 72:75-87

Galster G, Hanson R, Ratcliffe MR, Wolman H, Coleman S, Freihage J (2001) Wrestling sprawl to the ground: defining and measuring an elusive concept. Hous Policy Debate 12(4):681-717

Gordon P, Richardson HW (1997) Are compact cities a desirable planning goal? J Am Plan Assoc 63(1):95-106

Gordon P, Kumar A, Richardson HW (1989) The influence of metropolitan spatial structure on commuting time. J Urban Econ 26:138-151

Gordon P, Richardson HW, Jun MJ (1991) The commuting paradox: evidence from the top twenty. J Am Plan Assoc 57(4):416-420

Gordon P, Lee B, Richardson HW (2004) Travel trends in U.S. cities: explaining the 2000 census commuting results. University of Southern California, Los Angeles

Grazi F, Van der Bergh JC, Van Ommeren JN (2008) An empirical analysis of urban form, transport, and global warming. Energy $\mathrm{J}$ 29(4):97-122

Handy S (2005) Smart growth and the transportation-land use connection: what does the research tell us? Int Reg Sci Rev 28(2):146-167

Handy SL, Clifton KJ (2001) Local shopping as a strategy for reducing automobile travel. Transportation 28:317-346

Handy S, Cao X, Mokhtarian P (2005) Correlation or causality between the built environment and travel behavior? Evidence from Northern California. Transp Res Part D 10(6):427-444

Holden E, Norland IT (2005) Three challenges for the compact city as a sustainable urban form: household consumption of energy and transport in eight residential areas in the greater Oslo region. Urban Stud 42(12):2145-2166

Hong J, Shen Q, Zhang L (2013) How do built-environment factors affect travel behavior? A spatial analysis at different geographic scales. Transportation. doi 10.1007/s11116-013-9462-9
Jacobson MZ (2008) On the causal link between carbon dioxide and air pollution mortality. Geophys Res Lett 35. doi:10.1029/ 2007GL031101

Jerrett MR, Buenett T, Pope CA, Ito K, Thurston G, Krewski D, Shi Y, Calle E, Thun M (2009) Long-term ozone exposure and mortality. N Engl J Med 360(11):1085-1095

Knaap GJ, Song Y, Ewing R, Clifton K (2005) Seeing the elephant: multi-disciplinary measures of urban sprawl. National Center for Smart Growth Research and Education, Urban Studies and Planning Program, University of Maryland

Laden F, Schwartz J, Speizer FE, Dockery DW (2006) Reduction in fine particulate air pollution and mortality: extended follow-up of the Harvard six cities study. Am J Respir and Crit Care Med 173(6):667-672

Lariviere I, Lafrance G (1999) Modelling the electricity consumption of cities: effect of urban density. Energy Econ 21(1):53-66

Levinson DM, Kumar A (1994) The rational relocator: why travel times have remained stable. J Am Plan Assoc 301:495-519

Levinson DM, Kumar A (1997) Density and journey to work. Growth Change 28:147-172

Liao CH, Chang CL, Su CY, Chiueh PT (2013) Correlation between land-use change and greenhouse gas emissions in urban areas. Int J Environ Sci Tech 10(6):1275-1286

Malpezzi S (1999) Estimates of the measurements and determinants of urban sprawl in US metropolitan areas. University of Wisconsin, Center for Urban Land Economics Research, Madison (unpublished paper)

Marshall JD (2008) Energy-efficient urban form. Environ Sci Technol 42(9):3133-3137

Mokhtarian PL, Cao X (2008) Examining the impacts of residential self-selection on travel behavior: a focus on methodologies. Transp Res Part B 42(3):204-228

Nelson AC, Moore T (1996) Assessing growth management policy implementation: case study of the united states' leading growth management state. Land use Policy 13(4):241-259

Neuman M (2005) The compact city fallacy. J Plan Educ Res 25:11-26

Newman P, Kenworthy J (1989) Gasoline consumption and cities: a comparison of US cities with a global survey and its implication. J Am Plan Assoc 55(1):24-37

Niedt C, Martin IW (2013) Who are the foreclosed? A statistical portrait of America in crisis. Hous Policy Debate 23(1):159-176

Peiser R (2001) Decomposing urban sprawl. Town Plan Rev 72(3):275-298

Richmond HR (1995) Regionalism: Chicago as an American region. John D and Catherine T MacArthur Foundation, Chicago

Runhaar H, Driessen P, Soer L (2009) Sustainable urban development and the challenge of policy integration: an assessment of planning tools for integrating spatial and environmental planning in the Netherlands. Environ Plan 36(3):417-431

Sarzynski A, WomanHL Galster G, Hanson R (2006) Testing the conventional wisdom about land use and traffic congestion: the more we sprawl, the less we move? Urban Stud 43(3):601-626

Schweitzer L, Zhou J (2010) Neighborhood air quality, respiratory health, and vulnerable populations in compact and sprawled regions. J Am Plan Assoc 76(3):363-371

Song Y, Knaap G (2004) Measuring urban form: Is Portland winning the war on sprawl? J Am Plan Assoc 70(2):210-225

Stone B (2008) Urban sprawl and air quality in large US cities. J Environ Manag 86(4):688-698

Sultana S (2000) Some effects of employment centers on commuting times in the Atlanta metropolitan area, 1990. Southeast Geogr 41(2):225-233

Sultana S, Chaney P (2003) Impact of urban sprawl on travel behaviors and local watersheds in the Auburn-Opelika metropolitan area: a case study on a small MSA. Pap Proc Appl Geogr Conf 26:20-280 
Sultana S, Weber J (2013) The nature of urban growth and the commuting transition: endless sprawl or a growth wave? Urban Stud. doi:10.1177/0042098013498284

The Sierra Club (1999) The dark side of the American dream: the costs and consequences of suburban sprawl. The Sierra Club, San Francisco

Torrens PM, Alberti M (2000) Measuring sprawl. Working Paper Series, Paper-27, CASA: Centre for Advanced Spatial Analysis, University College London, London

Tsai Y (2005) Quantifying urban form: compactness versus 'sprawl'. Urban Stud 42(1):141-161

Tuzkaya U (2009) Evaluating the environmental effects of transportation modes using and integrated methodology and an application. Int J Environ Sci Technol 6(2):277-290

Wassmer R (2000) Urban sprawl in a US metropolitan area: ways to measure and a comparison of the Sacramento area to similar metropolitan areas in California and the US. CSUS Public Policy and Administration Working Paper, CA

Weber J, Sultana S (2007) Journey-to-work patterns in the age of sprawl: evidence from two midsize southern metropolitan areas. Prof Geogr 59(2):193-208

Weng Q (2003) Fractal analysis of satellite-detected urban heat island effect. Photogramm Eng Remote Sens 69(5):555-566

Yigitcanlar T, Teriman S (2014) Rethinking sustainable urban development: towards an integrated planning and development process. Int J Environ Sci Tech 1-12. doi:10.1007/s13762-013-0491-x

Zhao P, Lu B, de Roo G (2011) The impact of urban growth on commuting patterns in a restructuring city: evidence from Beijing. Pap Reg Sci 90(4):735-754

Zolnik EJ (2011) The effect of sprawl on private-vehicle commuting outcomes. Environ Plan-Part A 43(8):1875-1893. doi:10.1068/ a42466 